\title{
The Potential of in situ Rain Water Harvesting for Water Resources Conservation on Malaria Transmission in Tigray, Northern Ethiopia
}

\author{
Mekonnen Yohannes ${ }^{1 *}$ and Mitiku Haile ${ }^{2}$ \\ ${ }^{1}$ College of Health Sciences, Mekelle University, P.O. Box 1871, Private Bag 1959, Mekelle, \\ Ethiopia (*mekonnenyohannes@yahoo.co.uk) \\ ${ }^{2}$ College of Agriculture, P.O. Box 231, Mekelle University, Mekelle, Ethiopia
}

\begin{abstract}
The role of in situ rain water harvesting (RWH) in water resources conservation is well recognized in semiarid areas, such as the highlands of northern Ethiopia. However, in fringe areas of malaria endemicity, the potential impact of such schemes on vector populations and malaria transmission is not well documented. We therefore investigated the impact of such environmental interventions on Anopheles vector breeding and malaria burden, in a cross sectional survey undertaken in March/April 2005 in 4 villages in northwestern (3 in Hadegti and Hibret subdistricts; (s.d) 1800masl.) and central (Endachewa s.d.; 2050masl) zones of Tigray, in northern Ethiopia, where large scale construction of half-moon ponds (HMP) and ditches was in progress. A total of 990 blood slides taken from under 10 children revealed 268 infections of which $90.7 \%$ were $P$. falciparum, $7.5 \%$ P. vivax and $1.9 \%$ mixed. All of these were from Hadegti and Hibret s.d. where HMPs predominated, revealing a slide positivity rate of $35.6 \%$ (range $30.7-41.7 \%$ ) and $3.6 \%$, respectively. The majority ( $>77 \%$ ) of the malaria positive cases resided in households located within 750 meters of the RWH structures, indicating that proximity to mosquito breeding sites was an important determinant of malaria in the villages. Over $33.8 \%$ of the aquatic habitats in these villages were colonized by Anopheles aquatic stages, of which all were identified morphologically as An. gambiae sensu lato (presumably An. arabiensis). HMPs were found to be more productive than the smaller ditches, where water stayed longer for the aquatic stages to reach maturity to the adult mosquito. Hence, such environmental interventions require due consideration and need to be integrated with appropriate malaria control strategies.
\end{abstract}

Key words: In situ Rain water harvesting, Malaria, Anopheles arabiensis, Tigray, Ethiopia.

\section{INTRODUCTION}

In the Tigray highlands of Northern Ethiopia, the role of in situ rainwater harvesting (RWH) in water resources conservation is well recognized. Soil and water conservation (SWC) activities have long been in practice in Tigray, but the large scale and well organized program started over three decades ago (Esser et al., 2002). Since its large scale initiation, millions of hectares of sloppy areas have been treated by different SWC measures and tree seedlings planted in different parts of the region (BoANR, 2002). Initially, physical structures were mainly introduced (Chadhokar and Solomon Abate, 1988), such as the widespread stone bunds constructed along contour lines. Lately, particularly following the devastating drought and famine of the 1980s 
(Getachew Alem, 1999), these were supplemented by different RWH structures [e.g., semicircular micro catchments (half-moon ponds (HMPs), ditches, trenches, etc.], aimed at intercepting runoff water and improving infiltration and ground water recharge, thereby ensuring availability of water in springs and shallow wells. Farmers also cultivated their crops behind earthen barriers and ditches to increase their crop yield (Desta Gebremichael et al., 2005; Mintesinot Behailu and Mitiku Haile, 2002; Nyssen et al., 2004). Where rainfall is unevenly distributed and soils have high water-holding capacity, this system may store water for a prolonged period of time, impacting positively on the surrounding ecology and increased crop yield (Girmay Gebresamuel et al., 2004).

To date, as a result of the encouraging outcomes so far witnessed (Mintesinot Behailu and Mitiku Haile, 2002) and as part of the world wide effort to combat climate change, in situ RWH, along with other SWC activities, has gained renewed interest; and currently the scheme is in progress at an even larger scale. On the other hand, in semi-arid areas of fringe transmission, such as the Ethiopian Highlands, introduction or expansion of in situ RWH structures close to human habitations may lead to increased risk of malaria transmission, by creating more breeding habitat for vectors and increasing human - vector contact (Tedros Adhanom Ghebreyesus et al., 1999; Mekonnen Yohannes et al., 2005; Ijumba and Lindsay, 2001; Hunter et al., 1993). Compared to larger water bodies, such as dams, in situ RWH structures might have a much greater impact on malaria prevalence/incidence, as they are smaller, constructed in huge numbers in rural neighborhoods, producing enormous vector breeding surface. Anopheles arabiensis, the major vector of malaria in Ethiopia and perhaps the only important species in Tigray (Mekonnen Yohannes et al., 2005), shows a strong preference for such small, mostly turbid, rainwater pools that are often formed due to human activity and close to dwellings (Gillies and de Meillon, 1968). While the diverse effects of micro dams (Tedros Adhanom Ghebreyesus, et al., 1999) and ponds (Fitsum Hagos et al., 2006) have been the subjects of investigation in previous studies, the health and environmental effects of in situ micro rainwater harvesting structures for water resources conservation have not yet been studied. This paper presents the results of an investigation carried out in March/April 2005 on the impact of these structures on vector breeding and malaria transmission in selected villages of Tigray, northern Ethiopia. 


\subsection{Study area}

The study was conducted in March/April 2005 in three villages in Lailay Adiabo district located between $14^{\circ} 16^{\prime}-14^{\circ} 19^{\prime} \mathrm{N}$ and $38^{\circ} 11^{\prime}-38^{\circ} 14^{\prime} \mathrm{E}$; at 1,700-1,822 meters above sea level(masl) in northwestern zone of Tigray, where large scale construction of RWH structures was in progress (Fig.1). The three villages, namely Maisheru and Maigobo (in Hadegti subdistrict) and Enda-mariam (in Hibret subdistrict), are located about 25-35km northwest of Endaslassie town, the zonal capital. The villages were characterized by hundreds of HMPs and RWH ditches, with the former predominating. These are semicircular pits (radius $~ 3 \mathrm{~m}$ ), dug at 1-2 meters interval (laterally), where the excavated soil is used to construct a bund down stream of the pit. The bund height is about $25 \mathrm{~cm}$ after the soil has settled and this may be strengthened by stone bunds (Fig. 2). Spaced at about 3 meters, the HMPs are normally applied at a rate of about 300 hoops per hectare (Carruci, 1992; CFSCDD, 1986). A village (Aditegemes, in Endachewa subdistrict), located $45 \mathrm{~km}$ southeast of the town of Adwa, in the central zone of the region $\left(14^{\circ} 2^{\prime} 31.8834^{\prime \prime} \mathrm{N}\right.$ and 39 1' 49.044"E; 2059 masl), was included for comparative purposes, as the RWH structures constructed in the area constituted only of ditches and these were located relatively far away from the village. The RWH ditches in the study areas were about $25 \mathrm{~cm}$ deep by $50 \mathrm{~cm}$ wide, with soil bunds and constructed along the contour.

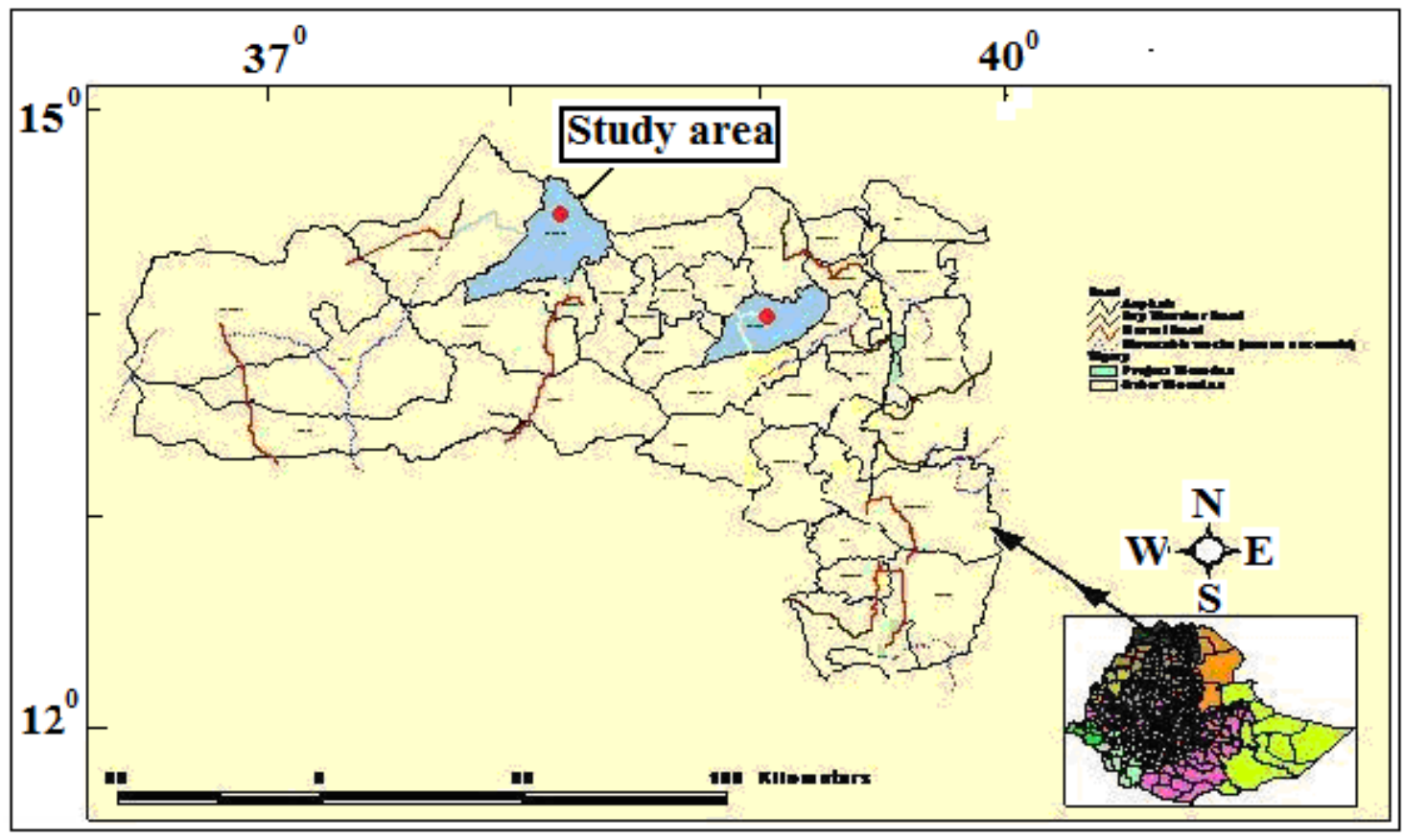

Figure1. Location map of the study sites in Lailay Adiabo (north western zone) and Endachewa districts in the Regional State of Tigray, northern Ethiopia. 


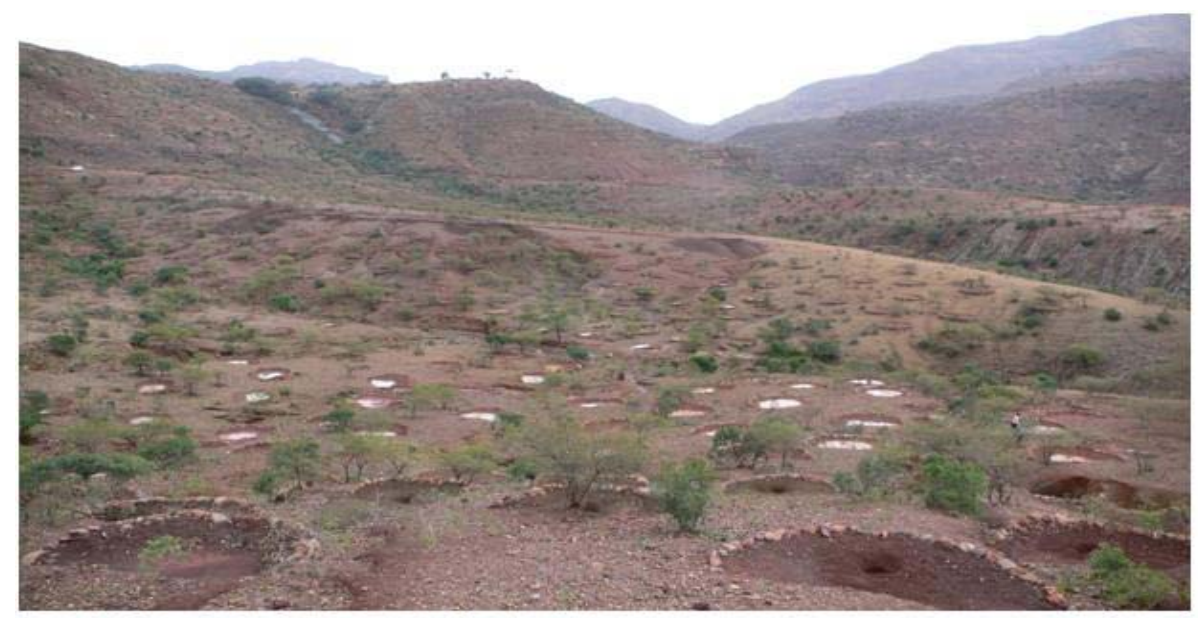

Figure 2. Half-moon ponds, promoted for water resources conservation in Tigray, northern Ethiopia.

The main study area in Lailay Adiabo district was characterized by scattered vegetation, dominated by Dodenia engusti, Cordia aftricana, Acacia spp, and Euclea shimperi trees and major soils of sand-silt, silt-clay and clay. Sorghum, millet, maize, teff (Eragrostis teff), and sesame are the major crops grown in the area. The study area drains to the Mereb River to the north and the unimodal rainy season (June to September) peaks in July and August. According to the nearest meteorological station in the town of Adidaero (rain guage only) (14²19' N, 38 $10^{\prime} \mathrm{E}$; 1822masl), which is found $4 \mathrm{~km}$ from the study village, nine years (2000 - 2008) average rainfall was $743 \mathrm{~mm}$ (ranges from 580.6 to $1057.2 \mathrm{~mm}$ ). The mean annual minimum and maximum temperatures from another station (at Endaslassie town), $35 \mathrm{~km}$ away, was $13.9^{\circ} \mathrm{C}$ and $27.7^{\circ} \mathrm{C}$, respectively.

The area is hypoendemic and prone to epidemics. One of the current study villages (Maisheru) served as a control in a previous study where an environmental impact assessment was in progress around a microdam, about 3km west of the village. The present study was prompted, when the inhabitants of the former study villages raised their concern about the possible impact of the newly introduced RWH structures on malaria transmission.

\section{MATERIALS AND METHODS}

\subsection{Parasitological survey}

The study involved collection of blood samples for prevalence of malaria infections in under 10 children. At the beginning of the survey, houses were numbered, demographic information 
collected, and the location of each house and the RWH structures in the study site boundaries were mapped by using a hand-held global positioning system (GPS) (Garmin, USA). Then, thick and thin blood films, made on the same slide, were collected from all children below the age of 10 for the presence of malaria parasites. These were stained in 3\% Giemsa and examined by experienced malaria control department personnel stationed in Endaslassie town. The stages of parasite in each malaria-positive slide were recorded. Children with parasitaemia were provided free treatment at a local health institution.

\subsection{Entomological survey}

All the water holding RWH structures in and around the study villages were searched for the presence of anopheline immature stages using standard dippers, at a rate of 6 dips per meter square. The breeding site characteristics of each habitat, including depth, surface area, condition of water (whether turbid, clear, etc), were recorded. Anopheline larvae and pupae were collected from positive habitats and pipetted into separate labeled vials where they were killed by gently heating the water in the vials to be preserved in $70 \%$ alcohol after draining the excess water. The immature mosquitoes were counted in three categories: early instars $\left(1^{\text {st }}\right.$ and $\left.2^{\text {nd }}\right)$, late instars $\left(3^{\text {rd }}\right.$ and $4^{\text {th }}$ ), and pupae. The $3^{\text {rd }}$ and $4^{\text {th }}$ anopheline stages were used to identify the particular anopheline species based on morphological descriptions (Verrone, 1962). For each household, the shortest distance to the nearest RWH structure was roughly calculated from the GPS coordinates, using the assumption that one degree of latitude/longitude is equivalent to $110 \mathrm{~km}$ in the equatorial region (Tedros Adhanom Ghebreyesus et al., 2003).

\section{RESULTS}

\subsection{Meteorological situation}

The rainfall profile of the study area in Lailay Adiabo district for a period of 5 years (2000 2005) is presented in figure 3. As indicated an early rainfall event of $44.3 \mathrm{~mm}$ was recorded in March 2005, compared to nil for the corresponding month in the preceding 4 years. A slightly higher average minimum temperature was also recorded for the same month, compared to corresponding figures in 2000 - 2004 (Fig. 4). 


\subsection{Demographic and parasitological findings}

The demographic profile and the results of the malaria prevalence study are summarized in Table 1. Of the 747 households constituting the four study villages, $71.4 \%$ (533) had under 10 children (1025), hence considered for the study. Among the 990 children (96.6\%) actually examined, 268 (27.1\%) infections were detected. Of these, 243 (90.7\%) were $P$. falciparum, 20 (7.5\%) were $P$. vivax, and 5 (1.9\%) were mixed infections. Over $90 \%$ of the $P$. falciparum positive slides, had ring stages of parasite. The majority of the infections were from two villages of Hadegti (Maigobo = 134; Maisheru $=126)$ and the rest were from Hibret (8) subdistrict, revealing a slide positivity rate of $35.6 \%(260 / 731)$ and $3.6 \%$ (8/223), respectively. None of the slides from Aditegemes village had parasites.

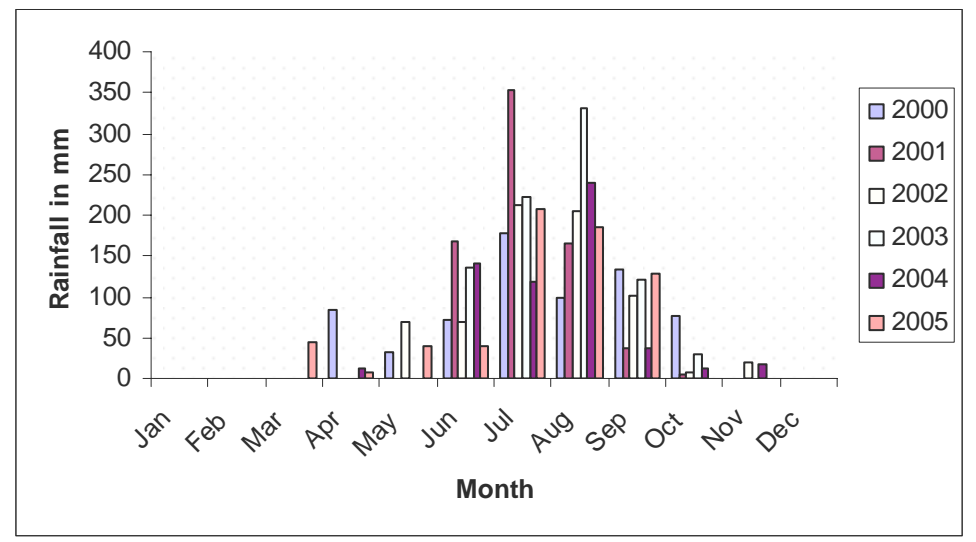

Figure 3. Monthly rainfall profile in the study villages (2000 - 2005) in northwestern Tigray, northern Ethiopia.

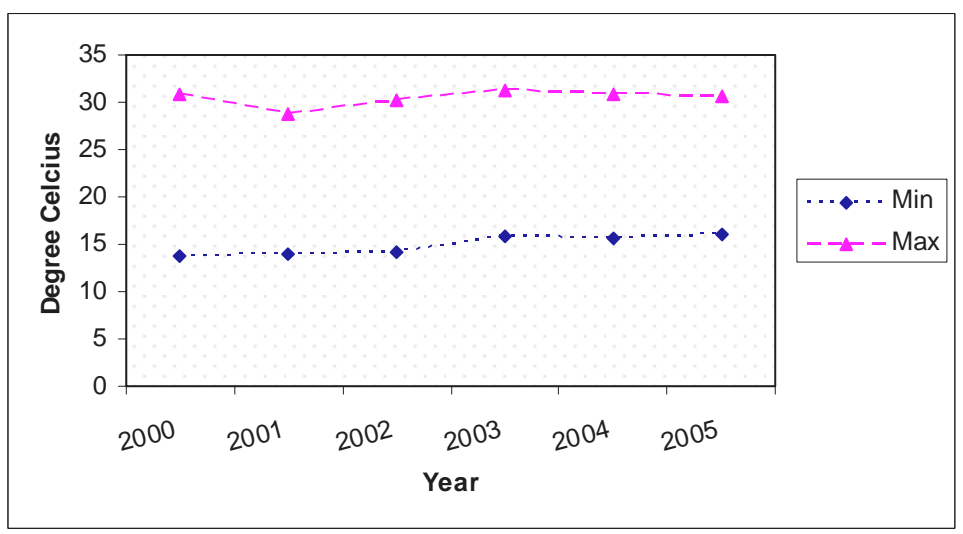

Figure 4. Average minimum and maximum temperatures that prevailed in the month of March in the study areas for a period of 2000 - 2005 in Tigray, northern Ethiopia.

About 51\% (176/344) of the households sampled from Hadegti and 4.8\% (8/167) from Hibret subdistricts had one or more cases of malaria. While all the eight affected households in Hibret 
had one malaria case each, in Hadegti 32\% (110/344) had 1 case; 14.8\% (51/344) had two, 3.8\% (13/344) had 3, $0.3 \%(1 / 344)$ had 4 and $0.3 \%(1 / 344)$ had 5 cases. On the average, there were 0.3 malaria episodes per household.

Overall, the presence of malaria cases in households was closely associated with distance to the RWH structures that served as vector breeding sites in the villages. This distance ranged from 5.9 to 1880 meters, with inter-village variations. Over $77 \%$ of the infections were found in households located within 750m from breeding sites (Table 2). Said differently, the malaria prevalence rate in under 10 children decreased with increasing distance of the households to the vector breeding sites. In Aditegemes village (Endachewa subdistrict), over $1233 \mathrm{RWH}$ ditches were dug and the nearest household to these structures was over 540 meters away. No infections were recovered from this village.

Table 1. Demographic characteristics and malaria prevalence survey results among under 10 year children in the four study communities in Tigray, northern Ethiopia (2005).

\begin{tabular}{|c|c|c|c|c|c|c|}
\hline \multirow[t]{2}{*}{ Characteristics /villages } & \multicolumn{3}{|c|}{ Hadegti (subdistrict) } & \multirow{2}{*}{$\begin{array}{l}\text { Hibret (sd) } \\
\text { Enda-mariam } \\
\text { No (\%) }\end{array}$} & \multirow{2}{*}{$\begin{array}{l}\begin{array}{l}\text { Enda- } \\
\text { chewa(sd) }\end{array} \\
\text { Aditegemes } \\
\text { No (\%) }\end{array}$} & \multirow[t]{2}{*}{ Total } \\
\hline & $\begin{array}{l}\text { Maigobo } \\
\text { No (\%) }\end{array}$ & $\begin{array}{l}\text { Maisheru } \\
\text { No (\%) }\end{array}$ & $\begin{array}{l}\text { Total } \\
\text { No (\%) }\end{array}$ & & & \\
\hline No Households & 251 & 249 & 500 & 317 & 30 & 747 \\
\hline No children $<10$ & 356 & 433 & 766 & 223 & 36 & 1025 \\
\hline Total population & 1128 & 1671 & 2799 & 1585 & 139 & 2938 \\
\hline No HMPs & 42 & 170 & 218 & 179 & & 397 \\
\hline No RWH Ditches & 0 & 48 & 48 & 0 & 1435 & 1483 \\
\hline No HHs sampled* & $157(62.5)$ & $187(75.1)$ & $344(68.8)$ & $167(52.7)$ & $22(73.3)$ & 533 \\
\hline No HHs with +ve cases & $85(54.1)$ & $91(48.7)$ & $176(51.2)$ & $8(4.8)$ & 0 & 184 \\
\hline No children sampled* & $321(90.2)$ & $410(94.7)$ & $731(95.4)$ & $223(100)$ & $36(100)$ & 990 \\
\hline No malaria +ve & $134(41.7)$ & $126(30.7)$ & $260(35.6)$ & $8(3.6)$ & 0 & 268 \\
\hline P. falciparum & $116(36.1)$ & $119(29)$ & $235(32.1)$ & $8(3.6)$ & 0 & 243 \\
\hline PfT** & 108 & 110 & 218 & 8 & 0 & 226 \\
\hline $\mathrm{PfG}^{* * *}$ & 8 & 9 & 17 & 0 & 0 & 17 \\
\hline P. vivax & $15(4.7)$ & $5(1.2)$ & $20(2.7)$ & 0 & 0 & 20 \\
\hline Mixed & $3(0.9)$ & $2(0.5)$ & $5(0.7)$ & 0 & 0 & 5 \\
\hline
\end{tabular}

* No of households with under 10 children sampled; **PfT = P. falciparum ring stages; ***PfG; $P$. falciparum gametocytes. 
Table 2. Number of malaria infected children in relation to distance of affected households to vector breeding sites (in meters)

\begin{tabular}{|llllll|}
\hline \begin{tabular}{l} 
Distance of $\begin{array}{l}\text { Noffect } \\
\text { affed }\end{array}$ \\
\cline { 2 - 6 }
\end{tabular} & Masiheru & Maigobo & Endamariam & total & Cumulative \\
\hline 150 & 24 & 12 & 0 & 36 & No (\%) \\
\hline 350 & 62 & 29 & 5 & 96 & $36(13.4)$ \\
\hline 550 & 27 & 28 & 0 & 55 & $132(49.3)$ \\
\hline 750 & 7 & 13 & 1 & 21 & $208(77.6)$ \\
\hline 950 & 4 & 18 & 0 & 22 & $230(85.8)$ \\
\hline 1150 & 2 & 14 & 0 & 16 & $246(91.8)$ \\
\hline 1350 & 0 & 3 & 1 & 4 & $250(93.3)$ \\
\hline 1550 & 0 & 5 & 0 & 5 & $255(95.1)$ \\
\hline 1750 & 0 & 9 & 1 & 10 & $265(98.9)$ \\
\hline 1880 & 0 & 3 & 0 & 3 & $268(100)$ \\
\hline
\end{tabular}

Table 3. Results of the RWH structures sampled for immature anopheline stages in the study villages in Tigray, northern Ethiopia (2005).

\begin{tabular}{|c|c|c|c|c|c|c|c|}
\hline \multirow[t]{3}{*}{ Characteristics } & \multicolumn{3}{|c|}{ Hadegti } & Hibret & \multicolumn{2}{|l|}{ Total } & Aditegemes \\
\hline & HMPs & RWHD & Total & HMPs & HMPs & All types & RWHD \\
\hline & No (\%) & No (\%) & No (\%) & No (\%) & No (\%) & No (\%) & No (\%) \\
\hline No sampled & 112 & 48 & 160 & 124 & 236 & 284 & 1233 \\
\hline Anopheles (An) +ve & $27(24.1)$ & $8(16.7)$ & 35 (21.9) & $26(21)$ & $53(22.5)$ & $61(21.5)$ & $17(1.4)$ \\
\hline An Larva (L) +ve & $23(20.5)$ & $6(12.5)$ & $29(18.1)$ & $26(70.3)$ & $49(20.8)$ & $55(90.2)$ & $17(1.4)$ \\
\hline An pupa (PU) +ve & $15(55.5)$ & $2(25)$ & $17(48.6)$ & $4(15.4)$ & $19(8.1)$ & $21(34.4)$ & 0 \\
\hline Total An. immature & 780 & 68 & 848 & 414 & 1194 & 1262 & 64 \\
\hline No. AnPU & 178 & 5 & 183 & 8 & 186 & 191 & 0 \\
\hline No. An L $3 \& 4$ & 161 & 0 & 161 & 195 & 356 & 356 & 0 \\
\hline No. dips made & 4602 & 361 & 4963 & 4726 & 9328 & 9689 & 10559 \\
\hline Anopheles /dip & 0.17 & 0.19 & 0.17 & 0.09 & 0.13 & 0.13 & 0.006 \\
\hline $\begin{array}{l}\text { Ratio: AnPU+ L }{ }_{3 \& 4} \text { : } \\
\text { AnL } 1 \& 2\end{array}$ & 0.77 & 0.08 & 0.68 & 0.96 & 0.8 & 0.8 & 0 \\
\hline No +ve dips & 1800 & 60 & 837 & 114 & 1914 & 1974 & 0 \\
\hline
\end{tabular}

Note: + ve = positive; $R W H D=$ Rain water harvesting ditches

\subsection{Entomological findings}

Among the 1517 RWH structures sampled in all the study villages, 5.1\% were positive for anopheles immature stages (Table 3). The degree of habitat colonization by anopheline immature stages was associated with proximity to human habitations. Thus, while just over one percent of the RWH ditches sampled in Aditegemes were positive for anopheline immature stages, anopheles breeding was observed in over $21 \%$ of the RWH structures sampled in the other three villages, with marked propensity in HMPs (22.5\% (53/236), compared to ditches (16.7\% (8/48). Overall, 1262 anopheline mosquito immature stages (715 early instars, 356 late instars and, 191 
pupae) were collected from the positive sites sampled (Table 3) in Hadegti and Hibret villages. All the late instars $\left(3^{\text {rd }} \& 4^{\text {th }}\right)$ were identified morphologically as An. gambiae sensu lato (presumably An. arabiensis). In Aditegemes only 64 early immature stages were recovered.

While all the anopheles positive ditches in Aditegemes village had early stage larval instars, over 34\% (21/61) of those in Hadegti and Hibret villages contained pupae, with marked difference between villages and types of the RWH structures. The highest pupal positivity rate (48.6\%; 17/35) was observed in Hadegti village, with HMPs showing the highest rate (55.6\%; 15/27), compared to the RWH ditches (25\%; 2/8). The overall pupal positivity in HMPs was 35.8\% (19/53). Similarly, the number of anopheline immature stages per dip was higher in HMPs. The ratio of late immature stages (plus pupae) to early stages, which is a rough measure of breeding site productivity, was also lower in RWH ditches but approached one in HMPs (Table 3).

\section{DISCUSSION}

Identifying the kind of environmental interventions that favor malaria vector breeding is vital for the elaboration of sound mosquito control strategies. The present study showed that construction of in situ RWH structures aimed at water resources conservation have the potential to increase the transmission of malaria substantially, if built near human habitations. In March/April, when transmission would be expected to be at its lowest in the study area, the present finding of malaria prevalence rates as high as $41 \%$ among children could mainly be attributed to the newly introduced RWH structures coupled with the unexpected rains in March 2005 (44.3mm), which was nil in the corresponding period of 2000 - 2004. Although seemingly insignificant, the slightly higher average monthly minimum temperature in March $2005\left(16{ }^{\circ} \mathrm{C}\right)$ compared to the corresponding period for $2004\left(15.6^{\circ} \mathrm{C}\right)$, might have also contributed its share. Rainfall not only provides breeding sites for mosquitoes in these structures, but also increases relative humidity necessary for mosquito survival, while temperature affects the development rates and survivorship of malaria parasites and, mosquito vectors, as well as the mosquito biting rates (Lindsay and Martens, 1998). Small increases in temperature near the lower limit for parasite and mosquito development would probably produce greater mosquito densities (Clements, 1992), higher biting rates (Lindblade et al., 2000; Lindsay and Birley 1996) and more rapid parasite development in the mosquito (Detinova, 1962). The parasite extrinsic incubation period (EIP) equation for $P$. falciparum demonstrates that at temperatures near the lower limit for parasite 
survival (i.e. around $16{ }^{\circ} \mathrm{C}$ ), small temperature changes have substantial effects on the number of days required for parasite development (Detinova, 1962). For instance, EIP is reduced from 55.5 to 38.2 days when temperature is increased from 18.0 to $18.9{ }^{\circ} \mathrm{C}$. In a previous study, the prevalence of malaria among children in one of the study villages (Maisheru) never exceeded 0.3\% during a two - year period in 1999 / 2000 (Mekonnen Yohannes et al., 2005).

The evidence of malaria parasitaemia was associated with proximity of households to larval habitats. Over $77 \%$ of the slide positive children came from households located within 500 - 750 meters from the RWH structures. This was supported by the entomological findings that revealed the RWH structures close to homesteads were predominantly colonized by mosquito immature stages, compared to those far away. This finding is consistent with other studies, where homes close to breeding sites exhibited higher mosquito abundance and malaria risks (Van der Hoek et al., 1998; Cano et al., 2006; Carter et al., 2000). This is because, as egg-laying is a spatial process depending upon the location of the focal habitat relative to sources of blood meal / gravid mosquitoes, habitats closer to human habitations tend to be favored by gravid mosquitoes and receive more eggs of An. arabiensis, and thus are known to be more productive for anopheline immatures (Zhou et. al., 2007).

Thus, the RWH structures provided favorable vector breeding habitats during the dry season, where larval habitats are more limited, and in hilly areas where surface waters cannot often accumulate sufficiently long to render mosquito aquatic stages complete the life cycle. The ratio of late larval instars and pupae to early instars, which is a rough measure of breeding site productivity, has approached one in HMPs, suggesting that they are more productive than the smaller RWH ditches, where water stayed longer for the aquatic stages to reach maturity to the adult mosquito. This is important for control measures since any small water body that remains for longer than one week will provide a potential breeding site. An. arabiensis is a pioneer species rapidly colonizing new water bodies and its aquatic stages mature to adults in about 7 10 days in sun-lit habitats (Gillies and de Meillon, 1968; Munga et al., 2006).

The association of surface water bodies with mosquito vector breeding is well established (Gillies and de Meillon, 1968; Hunter et al., 1993; Ijumba and Lindsay, 2001). Nevertheless, the present study has demonstrated that, in situ RWH structures built near villages, pose a much higher potential, compared to the bigger bodies of water, such as ponds (Kassahun Waktola, 2008), microdams (Tedros Adhanom Ghebreyesus et al., 1999; Mekonnen Yohannes et al., 2005; 
Boelee, 2003) and lakes (Lautze et al., 2007), as they are constructed in large numbers and provide numerous vector breeding sites over the vast rural settlements. These transient and mostly turbid surface waters are highly favored by An. arabiensis populations and are more difficult to control.

The presence of ring stage in 93\% of $P$. falciparum-positive subjects indicated that transmission was continuing at the time of the survey, suggestive of an impending outbreak of a greater magnitude. In fact, according to a report, based on a rapid assessment survey conducted in the area afterwards (August 2005), it was learnt that the situation escalated to epidemic proportions and the condition was out of control. A total of 26 deaths, ascribed to malaria, were reported from the study sites in Hadegti tabia (Yemane Ye-ebiyo, 2005). Nevertheless, unlike the devastating large scale epidemics experienced in East African highlands in the past (Zhou et al., 2004; Lindsay and Martens,1998), including the 1958 epidemic in Ethiopia that affected over 3 million people (Fontaine et al., 1961), the epidemic malaria that flared up in the study villages was spatially limited. Thus, the focal increase in malaria transmission, that appeared to be localized in two to three subdistricts, could be mainly be ascribed to the large scale introduction of the in situ RWH structures into the area. However, other factors might have also aggravated the situation, including, delay in taking preventive measures (spray operations were conducted late in August), absence of effective antimalarial drugs at the time (quinine and Fansidar were in use), and poor use of bed nets (Yemane Ye-ebiyo, 2005). Fansidar was officially replaced by Artemether-lumefantrine as first-line drug for $P$. falciparum since 2004 in the country, as resistance of $P$. faclicaprum infections to this drug was confirmed over wide areas (WHO, 2003). Nevertheless, even to date, where malaria prevalence has significantly decreased in the past 3-4 years in the region and the country at large, the health institution records of the past couple of years (including 2009) (unpublished data) showed increases in malaria episodes in the study areas and nearby villages, where the RWH structures were introduced. This is indicative of the potential impact of these structures on malaria transmission.

\section{CONCLUSION}

This study has demonstrated that large scale construction and/or expansion of in situ RWH structures, as a means of water resources conservation and food security, may lead to increased risk of malaria transmission if built near settlements by creating abundant mosquito breeding 
sites, increasing man - vector contact and extending the transmission season. In fringe areas of malaria endemicity, the potential impact of such schemes is tremendous as the population has little or no immunity and of the difficulty to control these structures, as they are very numerous and scattered over the vast landscape. The current plans to scale up the program will, therefore, need to be prudently handled so that, when possible, future construction of such structures will be sited at the highest feasible altitudes and as far away as possible from villages. Such schemes also need to be integrated with effective malaria control strategies, when applied in fringe areas of malaria transmission, such as the highlands of Tigray.

\section{ACKNOWLEDGEMENT}

The authors thank the residents of the study villages in Hadegti, Hibret and Endachewa subdistricts for their cooperation and participation in the study. This was prompted by the request of the inhabitants while undertaking a survey on microdams and ponds in these villages, with funds obtained from IWMI / sima and PREM, respectively. Hence, we would like to acknowledge them for we were able to conduct such an important study using the left over of these projects.

\section{REFERENCES}

BoANR. 2002. Soil and Water Conservation Annual Summary Report. Bureau of Agriculture and Natural Resource Development, Mekelle, Ethiopia, pp.1-35.

Boelee, E. 2003. Malaria in irrigated agriculture. Irrigation and Drainage, 52: 65-69.

Cano, J., Descalzo, M.A., Moreno, M., Chen, Z., Nzambo, S., Bobuakasi, L., Buatiche, J.N., Ondo, M., Micha, F \& Benito, A. 2006. Spatial variability in the density, distribution and vectorial capacity of anopheline species in a high transmission village (Equatorial Guinea). Malaria Journal, 5: 21.

Carter, R., Mendis, K.N \& Roberts, D. 2000. Spatial targeting of interventions against malaria. Bulletin of the World Health Organization, 78:1401-1411.

Carucci, V.F.P. 1992. CFSCDD. Technical notes on possible soil and water conservation measures for dry kola and dry weynadega agro-climatic zones, 32pp.

CFSCDD. 1986. Soil Conservation in Ethiopia, Guideline for Development Agents. Community forests and soil conservation development department (CFSCDD), Addis Ababa, 99pp. 
Chadhokar, P.A \& Solomon Abate. 1988. Importance of re-vegetation in soil conservation in Ethiopia. In: S. Richwanich, S. (ed.), Land Conservation for Future Generations. Proceedings of the $5^{\text {th }}$ International Soil Conservation Conference, Bangkok, Thailand, pp.1203- 1213.

Clements, A.N.1992. The Biology of Mosquitoes. Chapman and Hall, London.

Desta Gebremichael, Nyssen, J., Poesen, J., Deckers, J., Mitiku Haile, Govers, G \& Moeyersons, J. 2005. Effectiveness of stone bunds in controlling soil erosion on cropland in the Tigray Highlands, northern Ethiopia. Soil Use and Management; 21: 287-297.

Detinova, T.S. 1962. Age-Grouping Methods in Diptera of Medical Importance. Monograph Series 47. World Health Organization, Geneva.

Esser, K. Tor-Gunnar Vågen, Yibabe Tilahun \& Mitiku Haile. 2002. Soil conservation in Tigray, Ethiopia. Esser, Kjell, Noragric Report No. 5. Noragric, Centre for International Environment and Development Studies Agricultural University of Norway (NLH). Available at: http://www.nlh.no/noragric

Fitsum Hagos, Mekonnen Yohannes, Vincent Linderhofc, V., Gideon Krusemand, G., Aforki Mulugeta, Girmay Gebresamuel \& Zenebe Abreha. 2006. Micro water harvesting for climate change mitigation: Trade-offs between health and poverty reduction in Northern Ethiopia. PREM Working Paper: PREM 06/05, pp. 1-14. http://www.premonline.org/index.php?p=publications\&a=show\&id=117; Accessed in 09 March 2007.

Fontaine, R., Najjar, A \& Prince, S. 1961. The 1958 malaria epidemic in Ethiopia. American Journal of Tropical Medicine and Hygiene; 10: 795-803.

Getachew Alem. 1999. Rainwater harvesting in Ethiopia: an overview. $25^{\text {th }}$ WEDC Conference. Integrated development for water supply and sanitation, Addis Ababa, Ethiopia, pp. 387390: www.ucowr.siu.edu/proc/W8D.pdf; accessed in 29 July 2007.

Gillies, M.T \& de Meillon, B. 1968. The Anophelinae of Africa South of the Sahara (Ethiopian Zoogeographical Region). Publication of South Africa Institute of Medical Research, No. 54: 1-343.

Girmay Gebresamuel, Girmay Tesfay, Mitiku Haile, Dereje Assefa \& Abyot Legesse. 2004. Onfarm water harvesting for rainfed agriculture development and food security in Tigray: Investigation of technical and socioeconomic issues. Mekelle University, Faculty of Dryland Agriculture and Natural Resources. $1^{\text {st }}$ Year Activity \& Findings Report 
submitted to The Dryland Coordination Group Ethio-Sudan (DCG Ethio-Sudan) projects.

Hunter, J.M., Rey, L., Chu, K.Y., Adekolu-John, E.O \& Mott, K.E. 1993. Parasitic Diseases in Water Resources Development. The Need for Intersectoral Negotiation. WHO, 152pp.

Ijumba, J \& Lindsay, S.W. 2001. Impact of irrigation on malaria in Africa: paddies paradox. Medical and Veterinary Entomology, 15: 1- 11.

Kassahun Waktola. 2008. Malaria and pond-based rainwater harvesting linkages in the fringes of central highland Ethiopia. Rural and Remote Health, 8: 956. (Online). Available from: http://www.rrh.org.au. Accessed: 10 June 2010.

Lautze, J., McCartney, M., Kirshen, P., Olana, D., Jayasinghe, G \& Spielman, A. 2007. Effect of a large dam on malaria risk: the Koka reservoir in Ethiopia. Tropical Medicine and International Health, 12: 982-989.

Lindblade, K.A., Walker, E.D., Onapa, A.W., Katungu, J \& Wilson, M..L.2000. Land use change alters malaria transmission parameters by modifying temperature in a highland area of Uganda. Tropical Medicine and International Health, 5:263-274.

Lindsay, S.W \& Martens, W. 1998. Malaria in the African highlands: past, present and future. Bulletin of the World Health Organization; 76: 33-45.

Lindsay, S.W \& Birley, M.H. 1996. Climate change and malaria transmission. Annals of Tropical Medicine and Parasitology, 90: 573-588.

Mekonnen Yohannes, Mitiku Haile, Tewodros Adhanom Ghebreyesus, Witten, H.K., Asefaw Getachew, Byass, P \& Lindsay, S.W. 2005. Can source reduction of mosquito larval habitat reduce malaria transmission in Tigray, Ethiopia? Tropical Medicine and International Health, 10:1274-1285.

Mintesinot Behailu \& Mitiku Haile. 2002 Water harvesting in northern Ethiopia: environmental, health and socio-economic impacts. In: P.G., McCornick, A.B, Karma, G., Tadesse (eds.). Integrated water and land management research and capacity building priorities for Ethiopia. In: Proceedings, MoWR/EARO/IWMI/ILRI, International Workshop; 2-4 December, ILRI, Addis Ababa, Ethiopia, pp.185-191

Munga, S., Minakawa, N., Zhou, G., Mushinzimana, E., Barrack, O.J., Githeko, A.K. \& Yan, G. 2006. Association between land cover and production of malaria vectors in the western Kenyan highland. American Journal Tropical Medicine and Hygiene, 74: 69-75. 
Nyssen, J., Veyret-Picot, M., Poesen, J., Moeyersons, J., Mitiku Haile, Deckers, J. \& Govers, G. 2004. The effectiveness of loose rock check dams for gully control in Tigray, northern Ethiopia. Soil Use and Management, 20: 1-10.

Tedros Adhanom Ghebreyesus, Mitiku Haile, Witten, K. H., Assefaw Getachew, Ambachew Medhin Yohannes, Mekonnen Yohannes, Hailay Desta Teklehaimanot, Lindsay, S. W. \& Byass, P. 1999. Incidence of malaria among children living near dams in northern Ethiopia: community based incidence survey. British Medical Journal, 319: 663-666.

Tedros Adhanom Ghebreyesus, Byass, P., Witten, K. H., Assefaw Getachew, Mitiku Haile, Mekonnen Yohannes \& Lindsay, S. W. 2003. Appropriate Tools and Methods for Tropical Microepidemiology: a Case-study of Malaria Clustering in Ethiopia: Malaria Microepidemiology in Ethiopia. Ethiopian Journal of Health and Development, 17:1-8.

Van der Hoek, W., Konradsen, F., Dijkstra, D.S., Amerasinghe, P.H \& Amerasinghe, F.P. 1998. Risk factors for malaria: a microepidemiological study in a village in Sri Lanka. Transactions of the Royal Society of Tropical Medicine and Hygiene, 92: 265-269.

Verrone, G.A.1962. Outline for the determination of malarial mosquitoes in Ethiopia. Part II. Anopheline larvae. Mosquito News, 22:394-401.

WHO. 2003. Assessment and monitoring of antimalrial drug efficacy for the treatment of uncomplicated falciparum Malaria. www.malaria.who.int/docs/ProtocolWHO.pdf. Accessed June 2010.

Yemane Ye-ebiyo. 2005. A Report on Assessment of Malaria Epidemics in Laelay Adiabo and Raya Azebo woredas, Tigrai, Ethiopia. $1^{\text {st }}-5^{\text {th }}$ August. Center for Disease National Health Development in Ethiopia. The Earth Institute at Colombia University, pp.1-6.

Zhou, G., Minakawa, N., Githeko, A \& Yan, G. 2004. Association between climate variability and malaria epidemics in the east African highlands. PNAS, 101: 2375-2380.

Zhou, G., Munga, S., Minakawa, N. Githeko, A.K \& Yan, G. 2007. Spatial Relationship between Adult Malaria Vector Abundance and Environmental Factors in Western Kenya Highlands. American Journal of Tropical Medicine and Hygiene, 77: 29-35. 